\title{
Effectiveness of pneumococcal conjugate vaccination against invasive pneumococcal disease among children with and those without HIV infection: a systematic review and meta-analysis
}

\author{
Hossein Molavi Vardanjani ${ }^{1}$, Hodjat Borna ${ }^{2}$ and Ali Ahmadi ${ }^{{ }^{*}}$
}

\begin{abstract}
Background: HIV-infected children are at a higher risk of Invasive Pneumococcal Disease (IPD) and its mortality, even in the era of antiretroviral therapy. Therefore, an effective vaccination strategy would be beneficial. To investigate the effectiveness of Pneumococcal Conjugate Vaccination (PCV) against IPD among HIV-Infected and HIV-Uninfected Children through a systematic review and meta-analysis.
\end{abstract}

Methods: Observational studies and randomized trials on 7 years old or older children were searched in the Cochrane Library, Web of Science core collection, Embase, Medline/PubMed, and Google Scholar. Critical appraisal was done using the Cochrane risk of bias tool and the Newcastle-Ottawa quality assessment form. Effectiveness and efficacy of at least one dose of PCV was investigated among children with and without HIV considering subgroups of pneumococcal serotypes. We meta-analyzed the effect sizes using random-effects modeling.

Results: Efficacy of PCV was estimated as $45.0 \%(31.2,56.1)$ and $52.6 \%(25.7,69.8)$ among HIV-infected and HIV-uninfected children, respectively. Effectiveness of PCV among HIV-infected children as $-6.2 \%(-67.6,32.7)$ was significantly lower than HIV-uninfected children $65.1 \%(47.3,76.9)$. Effectiveness of PCV among HIVinfected children for IPDs caused by vaccine serotypes was estimated as 7.7(-66.7, 48.9), and for IPDs caused by non-vaccine serotypes was estimated as $-402.8(-1856,-29.2)$.

Conclusion: Unlike the evidence on the efficacy of PCV against IPD among both of HIV-infected and HIV-uninfected children, its effectiveness against IPD among HIV-infected children is much less limited.

Review registration: The study protocol was registered at PROSPERO (registration ID: CRD42018108187).

Keywords: Invasive pneumococcal disease, HIV, Children, Pneumococcal conjugate vaccine, Treatment outcome

\section{Background}

Children with HIV-infection (HI) are prone to invasive pneumococcal disease (IPD) roughly 40 times more than those without HIV-infection (HUI) [1, 2]. The risk of IPD-related mortality among them is higher than children without HIV-infection (HUI) [3, 4]. Prevention of IPD incidence is the most effective strategy to reduce

\footnotetext{
* Correspondence: ahmadi1919@gmail.com

${ }^{1}$ Molecular Biology Research Center, Systems Biology and Poisonings

Institute, Baqiyatallah University of Medical Sciences, Tehran, Iran

Full list of author information is available at the end of the article
}

the burden of IPD among children with HIV-infection (HI).

Of the most appropriate preventive strategies, for the time being, may be boosting the immune system function through antiretroviral therapy (ART) and/or vaccination against pneumococcal diseases [2]. Nevertheless, even after adopting ART, risk of incidence of IPD among children with HIV-infection (HI) remains high [5-7]. Therefore, effective vaccination can prove to be an important strategy for prevention of IPD and IPD-related mortality in $\mathrm{HI}[8,9]$.

(c) The Author(s). 2019 Open Access This article is distributed under the terms of the Creative Commons Attribution 4.0 International License (http://creativecommons.org/licenses/by/4.0/), which permits unrestricted use, distribution, and reproduction in any medium, provided you give appropriate credit to the original author(s) and the source, provide a link to the Creative Commons license, and indicate if changes were made. The Creative Commons Public Domain Dedication waiver (http://creativecommons.org/publicdomain/zero/1.0/) applies to the data made available in this article, unless otherwise stated. 
Currently, pneumococcal polysaccharide vaccines (PPVs) and pneumococcal conjugate vaccines (PCVs) are being used as effective immunizations against pneumococcal diseases in the general population $[7,8,10,11]$. PCVs were followed PPVs and formulized to compensate for the defective induced immunization by PPVs in younger children, via stimulation of T-cell dependent immune system and boosting anamnestic responses [12-15]. In 2000, PCV7 was licensed, and when some evidence showed replacement of non-vaccine serotypes, the prevalent replaced serotypes were added to the vaccine and PCV13 was formulated and licensed by $2010[16,17]$.

Although PCV (i.e. PCV13 and PCV7) are currently recommended for use in children under 2 years old, studies have demonstrated mixed reports including lower effectiveness of these vaccines against IPD in HI children [5, 18-20].

On the other hand, the recent review [21], though conducted by experienced specialists in the field, did not adopt a systematic approach for search and review; a defect which may results in biased findings. What is more, the existing pertinent reviews [21,22] have mainly focused on the findings of well-known randomized trials, which may cause the overestimation of the vaccines' effectiveness or biased findings, as an outcome of ignoring small studies and/or observational studies.

In this systematic review and meta-analysis of randomized trials and observational studies, we aimed at studying the efficacy and effectiveness of PCVs against IPD among children (younger than 7 years old) with and those without HIV-infection.

\section{Methods}

This systematic review and meta-analysis is reported in accordance with the Referred Reporting Items for Systematic Reviews and Meta-Analyses (PRISMA) statement [23]. The study was registered at the International Prospective Register of Systematic Reviews (registration ID: CRD42018108187).

The Cochrane Library, Web of Science core collection, Embase, Medline/PubMed, and Google Scholar were searched to identify English language reports published up to April 2018 (without any date restriction).

Appropriate combinations of pre-specified words, including "community acquired", "invasive pneumococcal disease", "pneumonia", "infection", "streptococcus", "bacteremia", "meningitis", "bacterial", "sepsis", "conjugate vaccine", "PCV", "Prevnar", "Prevenar", "PHiD-CV", "immunization", "vaccination", "protection", "effectiveness", "efficacy", "effect", "mortality", "impact", "benefit", "prevention", "control", "epidemiology", "hospitalization", "morbidity", and "incidence" were used. The bibliographies of reviews and other publications fully related to pneumococcal diseases were checked for additional reports.

Pre-post studies, time series, multiple interrupted time series, case-control studies, randomized trials, indirect cohort studies, case-coverage, case-cohort studies, and laboratory-based or population-based surveillance studies were eligible for inclusion into the study. Studies comparing vaccinated children to unvaccinated children in terms of IPD incidence (risk), or studies comparing children with and without IPD in terms of odds of any previous vaccination with PCVs were eligible for inclusion.

The issue of searching articles and their primary screening were conducted regardless of considering HIV infection status in participants, since some of the studies might have separately reported their results according to HIV status as study subgroups. Although our target population was children younger than 7 years old, to retrieve any article included this age group even as a subgroup in the text body (but not in the title or abstract). No age restriction was imposed during online searches.

Two primary outcomes of the study are the effectiveness and efficacy of PCVs for the prevention of IPD (i.e. all serotypes (AT IPD)) including meningitis, sepsis, and bacteremia. Our secondary outcomes were effectiveness and efficacy of PCV against non-vaccine serotypes (NVT IPD), and vaccine serotypes (VT IPD) IPDs, separately. Vaccine serotype IPD (VT IPD) indicates the infection by any of the PCV7, PCV9, PCV10, and PCV13 included serotypes.

Titles and abstracts of the publications were screened by two independent reviews to identify eligible publications. Then, full text of eligible publications identified in the previous steps as reviewed independently. Finally, only eligible studies that had reported their results separately by HIV status (i.e. HIV infected and/or HIV uninfected), were included in the critical appraisal phase of the study. The Cochrane risk of bias tool for randomized trials [24] and the most appropriate Newcastle-Ottawa quality assessment Form for nonrandomized studies [25] were used to assess the risk of bias. Appraised publications were categorized into three risk of bias groups, including high, unclear, and low risk, according to their obtained scores in critical appraisal.

A form was designed for data collection. According to a comprehensive literature review, a list of potentially correlated variables with the effectiveness and/or efficacy of vaccination in children as well as several methodological factors that may had some insidious effects on the results of the studies was provided. Then data collection form was provided accordingly. Afterwards, data were extracted into the data form. Disagreements over the screening and critical appraisal as well as extraction 
of data were discussed in the team until consensus was reached.

\section{Data analyses}

We pooled effect measures (i.e. relative risk (RR) or odds ratio (OR)) by subgroups of causative pneumococcal serotypes, study design, and HIV status (infected, and uninfected) by using Random-Effects model if meta-analysis was applicable. The DerSimonian and Larid method was applied.

Considering the well-evidenced issue of the probability of serotype replacement after the $\mathrm{PCV}$ vaccination, and also to show if the efficacy and effectiveness of the PCV vaccination is depended on the IPDs' causative serotypes, meta-analyses were done in three subgroups including IPDs caused by all serotypes (AT IPD, showing the overall results of the PCV vaccination); IPDs caused by vaccine-serotypes (VT IPD, showing the results of the PCV vaccination only against serotypes which are included in the PCVs; and IPDs caused by the non-vaccine serotypes (NVT IPD, showing the results of the PCV vaccination against IPDs which their causative serotypes are not included in the PCVs, in this case if the efficacy or effectiveness be a negative value it may be an evidence of serotype replacement).

In addition, as the results reported by the RCTs show estimates of the vaccine efficacy, while reported results by the observational study show estimates of vaccine effectiveness, all serotype-based subgroup meta-analyses were repeated according to the subgroups defined based on the study design (pre-post, case-control, and RCT).

The percentage of efficacy or effectiveness and their 95\% confidence interval were calculated using following formula:

$$
\text { Effectiveness } \%=(1-\text { Pooled Effect measure }) \times 100
$$

Where pooled effect measure was "pooled RR" or "pooled OR" according to the study design.

If an individual study had reported RR/OR for different subgroups (e.g. for subgroups by causative serotypes of IPD), its subgroup specific RR/ORs considered independent and were pooled by using Random-Effects model.

As in the meta-analysis studies a crucial criterion for doing meta-analysis is a relative homogeneity of the observed primary effect measures (in this study efficacy and/ or effectiveness), we assess homogeneity of the primary effect measures. In a simplified word, homogeneity means that the sampling population of each of the included primary studies is adequately similar with the sampling population of the other studies. Meta-analysis of effect measures from studies with different sampling populations results in an apple-orange juice. The $\mathrm{Q}$ test and the $\mathrm{I}^{2}$ test were used to assess heterogeneity of individual estimates. In the cases of high heterogeneity, meta-regression models were fitted to identify variables affecting this heterogeneity by using restricted maximum likelihood technique. Meta-regression is a technique to identify determinants of differences between the sampling population of the primary studies (i.e. heterogeneity).

L'Abbe and Galbraith plots were used to identify influential studies. Egger and Funnel plot tests were used to evaluate for publication bias in each study subgroups. We also used sensitivity analysis to evaluate the effect of each individual estimates on the pooled effect measure. The data were analyzed using Stata version 11.2 (Stata Corporation, College Station, TX, USA).

\section{Results}

\section{Overview of included studies and participants}

A total of 23,616 articles identified, of which 1864 were screened to be included in the full text review (Fig. 1).

Ten studies were included in the study. Out of these, one was conducted in the USA and nine studies in the South Africa. No cohort study was identified. The analyzed data includes $1332 \mathrm{HI}$ and $3462 \mathrm{HUI}$ children in three case-control studies; $2577 \mathrm{HI}$ and 37,259 HUI children in three randomized trials; and 48,550 $\mathrm{HI}$ and 2, 272,443 HUI children in four pre-post studies (Table 1).

\section{Overall and subgroup-specific pooled estimates of efficacy/effectiveness}

Almost all of the included studies had reported their results for overall IPD, but not for meningitis, sepsis, or bacteremia, separately. Based on case-control studies, the overall effectiveness of PCVs against any IPD was estimated as $-6.2 \%$ (95\% CI: $-67.6,32.7$, Fig. 2) and 65.1\% (95\% CI: 47.3, 76.9, Fig. 3) among HI and HUI children, respectively. Based on randomized trials, the overall efficacy among $\mathrm{HI}$ and HUI children was estimated 45.0\% (31.2, 56.1, Fig. 4) and 52.6\% (25.7, 69.8, Fig. 5), respectively.

Because of high heterogeneity, we are unable to metaanalyze the individual estimates reported by pre-post studies, however, meta- analysis was done in some subgroups with moderate heterogeneity (Table 2).

The heterogeneity of individual studies was also high in subgroups, especially in pre-post studies.

\section{Determinants of heterogeneity of results by subgroups}

The $\mathrm{I}^{2}$ index, for pre-post results, was $85.2 \%$ with a $P$ value of $<0.001$ for AT IPDs among HI children (showing that meta-analysis is not justifiable in this subgroup), $75.4 \%(P<0.001)$ for VT IPDs (showing that meta-analysis is not justifiable in this subgroup), and $15.5 \%(P=0.316$, showing that meta-analysis is justifiable in this subgroup) for NVT IPDs (Additional file 1: Figure S1). 


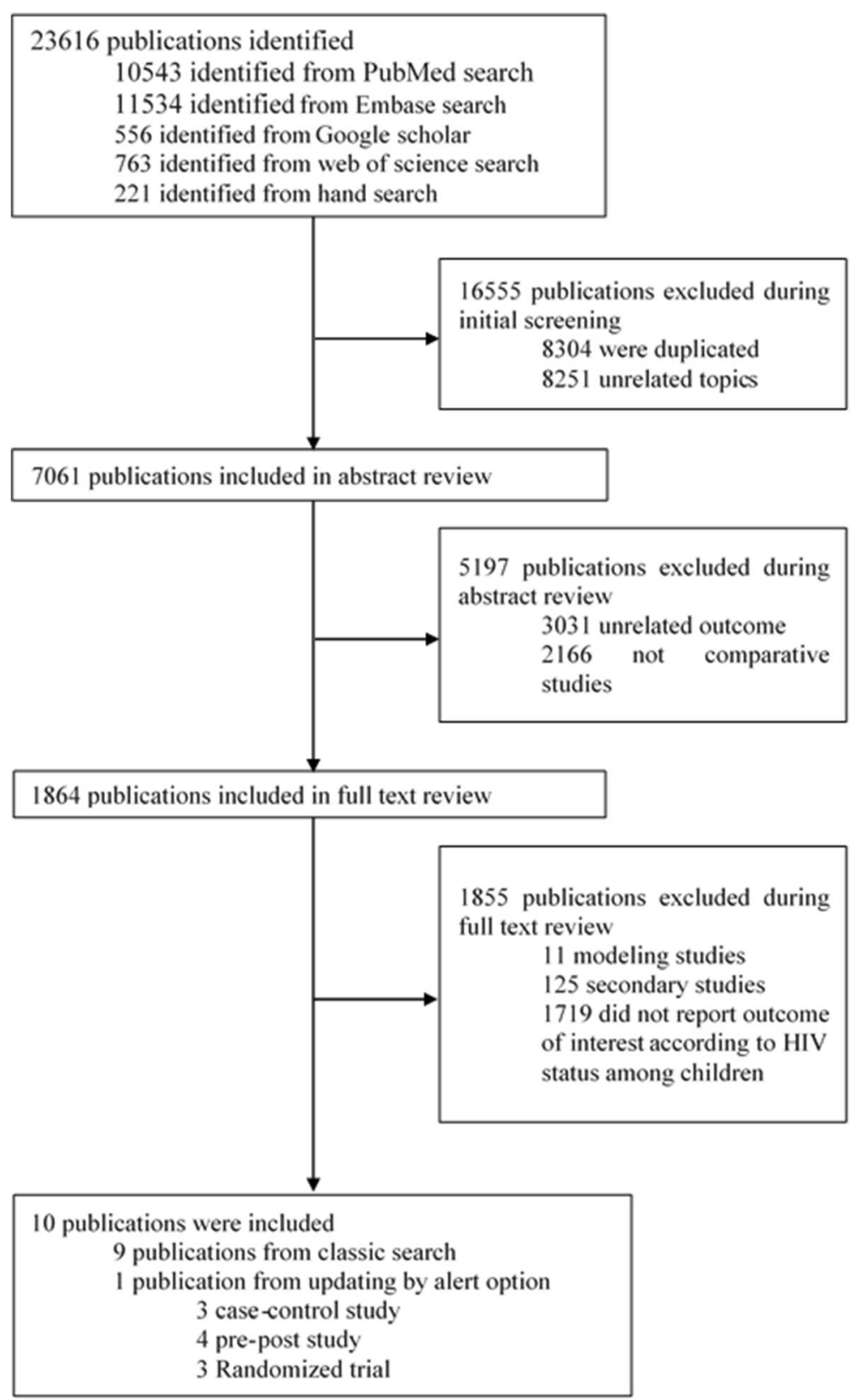

Fig. 1 Study selection flow diagram

The age group $(P=0.019)$, the vaccine valency $(P=0.012)$, the vaccination schedule $(P=0.002)$, the time after the introduction of the vaccination program in the population $(P=$ 0.027 ), the percentage of children received a booster dose $(P=0.05)$, and the IPD diagnostic method $(P=0.04)$ involved in this heterogeneity (factors which may be the underlying causes of different sampling populations of the included studies)). These factors were quite different depending on the type of outcome and the HIV-infection status.

Among HUI children, the $\mathrm{I}^{2}$ index for heterogeneity of the pre-post studies was estimated as $93.7 \%(P<0.001)$ for AT IPD, 92.3\% $(P<0.001)$ for VT IPD, and $66.9 \%$ $(P=0.006)$ for NVT IPD (Additional file 1: Figure S2). The percentage of the population who had received a booster dose $(P=0.004)$, the vaccination schedule $(P=$ $0.012)$, the time passed from the beginning of the vaccination program $(P=0.011)$, and the vaccine valency $(P=0.047)$ were the effective factors on the heterogeneity of results in HUI children.

The $\mathrm{I}^{2}$ index for the case-control studies was estimated as $0.0 \%(P=0.825) ; 11.7 \%(P=0.931)$; and $0.0 \%(P=$ 0.579 ) for AT, VT and NVT IPDs among HI children, 
Table 1 Publications included in meta-analysis

\begin{tabular}{|c|c|c|c|c|c|c|c|c|c|}
\hline No. & Author & $\begin{array}{l}\text { HIV } \\
\text { infe. }\end{array}$ & Vaccine & Outcome & Age group & Schedule & Study design & $\begin{array}{l}\text { Sample } \\
\text { size }\end{array}$ & $\begin{array}{l}\text { Risk of } \\
\text { bias }\end{array}$ \\
\hline 1 & $\begin{array}{l}\text { Klugman et } \\
\text { al. [20] }\end{array}$ & $\begin{array}{l}\mathrm{HI}, \\
\mathrm{HUI}\end{array}$ & PCV9 & $\begin{array}{l}\text { First episode of IPD: All serotype, } \\
\text { vaccine and non-vaccine serotypes; } \\
\text { during } 2.3 \text { years of follow up }\end{array}$ & $\begin{array}{l}\text { Less than } 5 \\
\text { years }\end{array}$ & $\begin{array}{l}3 \text { doses at } 6,10,14 \mathrm{WK} ; \\
\text { no booster dose }\end{array}$ & $\begin{array}{l}\text { Randomized } \\
\text { trial }\end{array}$ & 39,836 & Low \\
\hline 2 & $\begin{array}{l}\text { Madhi et } \\
\text { al. [26] }\end{array}$ & $\begin{array}{l}\mathrm{HI}, \\
\mathrm{HUI}\end{array}$ & PCV9 & $\begin{array}{l}\text { First episode of IPD: All, vaccine } \\
\text { and non-vaccine serotypes; } \\
\text { during } 6.16 \text { years of follow up }\end{array}$ & $\begin{array}{l}\text { Less than } 7 \\
\text { years }\end{array}$ & $\begin{array}{l}3 \text { doses at } 6,10,14 \mathrm{WK} ; \\
\text { no booster dose }\end{array}$ & $\begin{array}{l}\text { Randomized } \\
\text { trial }\end{array}$ & 39,836 & Low \\
\hline 3 & $\begin{array}{l}\text { Madhi et } \\
\text { al. [27] }\end{array}$ & $\begin{array}{l}\mathrm{HI}, \\
\mathrm{HUI}\end{array}$ & PCV9 & $\begin{array}{l}\text { Bacteremic pneumococcal } \\
\text { pneumonia : all and vaccine } \\
\text { serotypes; during } 2.3 \text { years of } \\
\text { follow up }\end{array}$ & $\begin{array}{l}\text { Less than } 5 \\
\text { years }\end{array}$ & $\begin{array}{l}3 \text { doses at } 6,10,14 \mathrm{WK} \\
\text { no booster dose }\end{array}$ & $\begin{array}{l}\text { Randomized } \\
\text { trial }\end{array}$ & 39,836 & Low \\
\hline 4 & $\begin{array}{l}\text { Cohen et } \\
\text { al. [19] }\end{array}$ & $\begin{array}{l}\mathrm{HI}, \\
\mathrm{HUI}\end{array}$ & PCV7 & IPD: All and PCV7 serotypes & $\begin{array}{l}\text { Less than } 1 \\
\text { year }\end{array}$ & $\begin{array}{l}2+1 \text { at } 6 \text { and } 14 \text { WK, and } 1 \\
\text { at } 9 \text { month (two or more) }\end{array}$ & $\begin{array}{l}\text { Matched } \\
\text { case control }\end{array}$ & 1395 & Low \\
\hline 5 & $\begin{array}{l}\text { Cohen et } \\
\text { al. [18] }\end{array}$ & $\begin{array}{l}\mathrm{HI} \\
\mathrm{HUI}\end{array}$ & PCV13 & $\begin{array}{l}\text { IPD: All, PCV7 and PCV13 } \\
\text { serotypes }\end{array}$ & $\begin{array}{l}\text { Less than } 5 \\
\text { years }\end{array}$ & $\begin{array}{l}2+1 \text { at } 6 \text { and } 14 \text { WK, and } 1 \\
\text { at } 9 \text { months (two or more) }\end{array}$ & $\begin{array}{l}\text { Matched } \\
\text { case control }\end{array}$ & 1716 & Low \\
\hline 6 & $\begin{array}{l}\text { Mollendorf } \\
\text { et al. [28] }\end{array}$ & $\mathrm{HUI}$ & PCV7 & IPD: vaccine serotypes ${ }^{a}$ & $\begin{array}{l}\text { Less than } 5 \\
\text { years }\end{array}$ & $\begin{array}{l}2+1 \text { at } 6 \text { and } 14 \text { WK, and } 1 \\
\text { at } 9 \text { months (two or more) }\end{array}$ & $\begin{array}{l}\text { Matched } \\
\text { case control }\end{array}$ & & low \\
\hline 7 & $\begin{array}{l}\text { Steenhoff } \\
\text { et al. [29] }\end{array}$ & $\mathrm{HI}$ & PCV7 & $\begin{array}{l}\text { IPD: vaccine and non-vaccine } \\
\text { serotypes }\end{array}$ & $\begin{array}{l}\text { Less than } 5 \\
\text { years }^{\mathrm{a}}\end{array}$ & $\begin{array}{l}3+1 \text { at } 2,4,6 \text { and } 12-15 \\
\text { months }\end{array}$ & $\begin{array}{l}\text { Retrospective } \\
\text { Pre-post }\end{array}$ & 256 & unclear \\
\hline 8 & $\begin{array}{l}\text { Nzenze et } \\
\text { al. [30] }\end{array}$ & $\begin{array}{l}\mathrm{HI} \\
\mathrm{HUI}\end{array}$ & $\begin{array}{l}\text { PCV7, } \\
\text { PCV13 }\end{array}$ & $\begin{array}{l}\text { IPD: All, PCV7, PCV13 and } \\
\text { non-vaccine serotypes }\end{array}$ & $\begin{array}{l}\text { Less than } 2 \\
\text { and } 2-5 \\
\text { years }\end{array}$ & $\begin{array}{l}2+1 \text { at } 6 \text { and } 14 \mathrm{WK} \text {, and } 1 \\
\text { at } 9 \text { months }\end{array}$ & Pre-post & 160,000 & unclear \\
\hline 9 & $\begin{array}{l}\text { Gottberg } \\
\text { et al. [5] }\end{array}$ & $\begin{array}{l}\mathrm{HI} \\
\mathrm{HUI}\end{array}$ & $\begin{array}{l}\text { PCV7, } \\
\text { PCV13 }\end{array}$ & $\begin{array}{l}\text { IPD: All, PCV7, PCV13 and } \\
\text { non-vaccine serotypes }\end{array}$ & $\begin{array}{l}\text { Less than } 2 \\
\text { years }\end{array}$ & $\begin{array}{l}2+1 \text { at } 6 \text { and } 14 W K \text {, and } 1 \\
\text { at } 9 \text { months }\end{array}$ & $\begin{array}{l}\text { National } \\
\text { Pre-post }\end{array}$ & $\begin{array}{l}\approx 2,000 \\
000\end{array}$ & Unclea \\
\hline 10 & $\begin{array}{l}\text { Mollendorf } \\
\text { et al. [4] }\end{array}$ & $\begin{array}{l}\mathrm{HI}, \\
\mathrm{HUI}\end{array}$ & PCV13 & IPD: All serotypes & $\begin{array}{l}\text { Less than } 1 \\
\text { year }\end{array}$ & $\begin{array}{l}2+1 \text { at } 6 \text { and } 14 \mathrm{WK} \text {, and } 1 \\
\text { at } 9 \text { months }\end{array}$ & Pre-post & $937^{a}$ & Unclear \\
\hline
\end{tabular}

Abbreviations: WK Weeks, HI HIV-infected, HUI HIV-uninfected, IPD invasive pneumococcal disease, $P C V$ pneumococcal conjugate vaccine

${ }^{a}$ Due to methodological considerations or unavailability of primary information only this part of results was included in the meta-analysis

respectively (Fig. 2, showing that meta-analysis is justifiable in each of these subgroups).

The $\mathrm{I}^{2}$ index, of case-control results for HUI children, was estimated as $0.0 \%(P=0.497) ; 0.0 \%(P=0.949)$; and $0.0 \%(P=0.589)$, respectively for AT, VT and NVT IPDs (Fig. 3, again as above).

The vaccination schedule $(P=0.039)$, the vaccine valency $(P=0.005)$, and the percentage of children who received a booster dose $(P=0.042)$, were the effective factors on the heterogeneity of results in the case-control studies.

The $\mathrm{I}^{2}$ index for reported results of randomized trials was low and estimated as $0.0 \%(P=0.539)$, and $0.13 .2 \%(P=0.329)$ among $\mathrm{HI}$ and HUI children, respectively (Figs. 4 and 5).

\section{Age subgroups}

In pre-post studies, because of the high heterogeneity of results in age subgroups both in HI and HUI children, we did not meta-analysis (Additional file 1: Figure S3 and Figure S4).

Although the results of the case-control studies were not heterogeneous among $\mathrm{HI}$ children, they involved only the age group younger than $2.5\left(\mathrm{VE} \%=-6.2 ; \mathrm{I}^{2}=\right.$ $0.0 \%$; Fig. 2). The results of these studies had moderate heterogeneity for HUI children $\left(\mathrm{I}^{2}=51.5 \%\right.$; $\left.P=0.011\right)$.
The effectiveness of the PCV was estimated by agegroup (as a determinant of vaccine efficacy/ effectiveness) as follow: $84.0 \%(62.0,93.0)$ for children younger than 5 and $62.2 \%(42.7,75.0)$ for children younger than 2.5 (Additional file 1: Figure S5 and Figure S6).

According to the randomized trials, the efficacy of the PCV in HI children was $48.7 \%(11.9,70.1), 49.9 \%(17.8$, 69.4 ) and $39.1 \%(14.8,56.4)$, for children younger than 2.5, 5, and 7 years old, respectively (Additional file 1: Figure S7). In addition, these values for HUI children were $51.0 \%(-67.0,86.0), 50.0 \%(-25.5,80.0)$, and 58.7\% ($16.8,85.4$ ), respectively (Additional file 1: Figure S8).

\section{Vaccine valency subgroups}

Due to high heterogeneity, conducting a meta-analysis in pre-post studies was not applicable based on the vaccine valency (Additional file 1: Figure S9 and Figure S10). The effectiveness was estimated in the case-control studies (Table 3, and Additional file 1: Figure S11 \& Figure S12) by vaccine valency (vaccine valency is an important determinant of the PCVs efficacy and/ or effectiveness, as the preventive effect of typeable PCVs is a function of the serotypes added in the vaccine). 


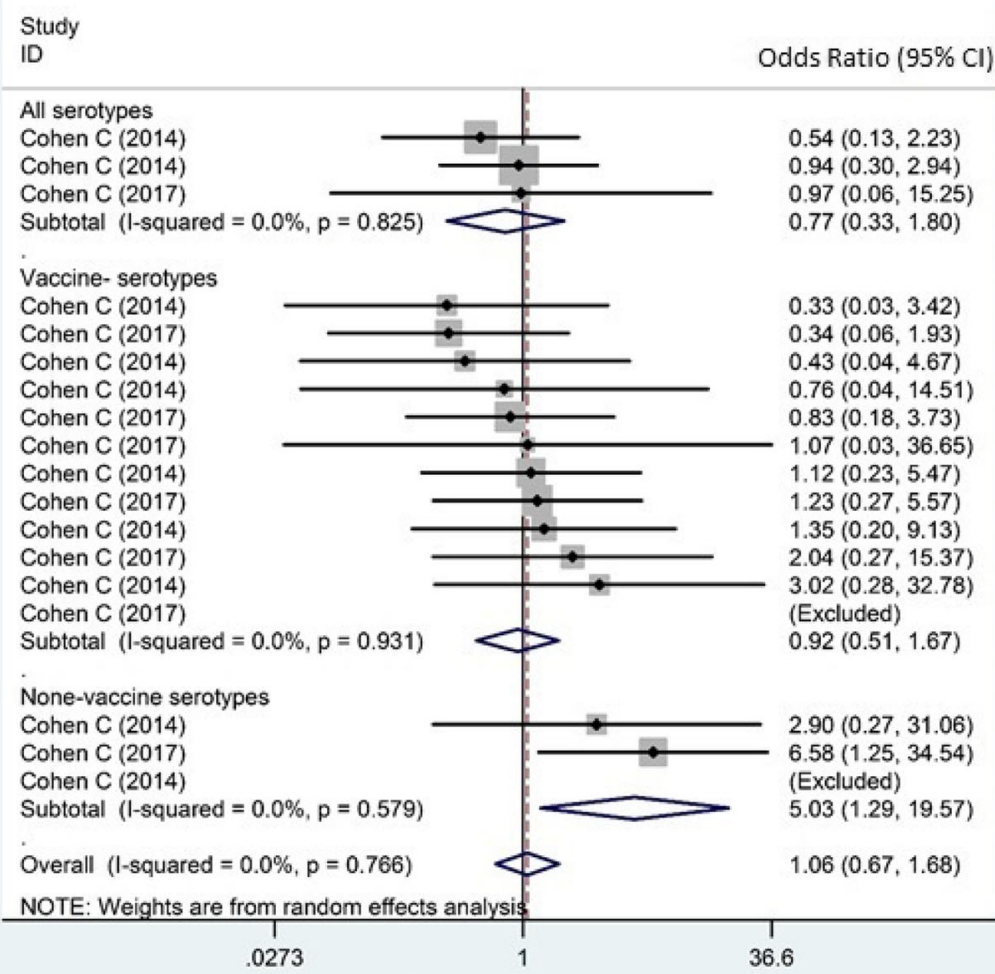

Odds Ratio

Fig. 2 Forest plot of the effectiveness (VE \%) of pneumococcal conjugate vaccines against invasive pneumococcal disease among HIV-infected children according to case-control studies

Randomized trials had only reported the efficacy of PCV9 (Figs. 4 and 5).

\section{Sensitivity analysis and assessment of publication bias}

The results of sensitivity analysis showed that despite of some variations in individual estimates, none was influential (Additional file 1: Figures S13-18). As there was no study with poor appraisal score, no sensitivity analysis was done with regard of the quality of publications. The results of funnel plot and Egger's test for publication bias in randomized trials $(P$-value $\mathrm{HI}=$ $0.358, P$-value HUI $=0.839$, Additional file 1 : Figures S19-S20), case-control studies $\left(\mathrm{P}_{\mathrm{HI}}=0.210, \mathrm{P}_{\mathrm{HUI}}=\right.$ 0.419, Additional file 1: Figures S21-S22), and pre-post studies $\left(\mathrm{P}_{\mathrm{HI}}=0.192, \mathrm{P}_{\mathrm{HUI}}=0.254\right.$, Additional file 1 : Figures S23-S24) showed a lack of publication bias.

\section{Discussion}

In this systematic review and meta-analysis, we pooled the available data on the efficacy and effectiveness of PCVs against IPD among HI and HUI children, as well as correlates of heterogeneity of the effect of PCV to prevent IPD. The results showed that the overall effectiveness (efficacy in the real situation) of PCVs in preventing IPD (including both of vaccine or non-vaccine serotype IPDs) among HI children was significantly lower than HUI children (-6.2\% vs. $65.1 \%)$. It may be due to higher rates of NVT IPD in HI children compared to HUI children (VE for NVT: in HI, $-403 \%$ VS in HUI, $-21 \%)$. However, the pooled efficacy among children with and without HIV was not significantly different (45.0\% vs. $52.6 \%)$.

The higher efficacy by randomized trials compared to observational studies in a non-differential direction, is an expected and documented issue [17, 31]. However, the differences observed in our study results was differential and reverse, as the effectiveness of vaccination among $\mathrm{HI}$ children was $52 \%$ less than its efficacy $(-6.2$ of effectiveness VS $45 \%$ of efficacy), but $12 \%$ more than efficacy among HUI children (65\% of effectiveness VS $53 \%$ of efficacy). The higher PCV efficacy (compared with its effectiveness) in $\mathrm{HI}$ children might be interpretable as a result of the more available cares for participants of randomized trials (such as higher percentage of receiving $A R T$, higher rate of vaccination, and also timeliness vaccination) compared to real population. Accordingly, 
All serotypes

Cohen C (2014)

Cohen C (2017)

Cohen C (2014)

Subtotal (I-squared $=0.0 \%, p=0.497$ )

Vaccine-serotypes

Cohen C (2014)

Cohen C (2017)

Cohen C (2017)

Mollendorf C (2015)

Cohen C (2014)

Cohen C (2017)

Cohen C (2017)

Cohen C (2014)

Cohen C (2014)

Subtotal (1-squared $=0.0 \%, p=0.949$ )

None-vaccine serotypes

Cohen C (2014)

Cohen C (2017)

Cohen C (2014)

Subtotal (l-squared $=0.0 \%, p=0.589$ )

Overall (l-squared $=51.5 \%, p=0.011$ )

NOTE: Weights are from random effects analy $y$ sis

0108
Odds Ratio $(95 \% \mathrm{Cl})$

$0.37(0.13,1.03)$

$0.48(0.21,1.11)$

$0.71(0.40,1.27)$

$0.57(0.37,0.88)$

$0.10(0.01,0.93)$

$0.10(0.02,0.48)$

$0.15(0.04,0.60)$

$0.16(0.07,0.38)$

$0.19(0.04,0.85)$

$0.22(0.09,0.54)$

$0.23(0.06,0.86)$

$0.26(0.09,0.75)$

$0.34(0.11,1.02)$

$0.20(0.13,0.30)$

$0.79(0.13,4.85)$

$0.85(0.25,2.89)$

$1.76(0.64,4.84)$

$1.21(0.59,2.48)$

$0.35(0.23,0.53)$

92.7

\section{Odds Ratio}

Fig. 3 Forest plot of the effectiveness (VE \%) of pneumococcal conjugate vaccines against invasive pneumococcal disease among HIV-uninfected children according to case-control studies

improvement in the accessibility and utilization of the routine healthcare available for $\mathrm{HI}$ children in addition of extending the range of such services may be measures to increase the PCV effectiveness among this population.

Higher PCV effectiveness against VT IPD among HUI children might be due to indirect effects of other vaccination programs (such as vaccination with PPV23 or Influenza vaccine), and/or also induced herd immunity by PCV vaccination, explaining the $7.7 \%$ effectiveness against VT IPDs among HI children compared to 51\% in HUI children [32-35].

The difference between the effectiveness and efficacy of PCVs in HI children was - 25\% against AT IPD, $383 \%$ against NVT IPD, and only $-43 \%$ against VT IPD. This is while, surprisingly in HUI children, the effectiveness of PCVs against NVT IPD was improved up to about $280 \%$ compared with the efficacy. This major difference might be due to a serious situation - for example, replacement of vaccine-serotypes and, especially non-vaccine serotypes in $\mathrm{HI}$ children happens faster and more than in HUI children [36-38]. The pattern of replaced serotypes in HI children would be so important since vaccination may operate reversely on these children, and higher-valency vaccines or vaccines with high level of cross-serotype protection might be needed after a short period of time [39, 40]. This probable serotype replacement may be a result of a type of false assurance after vaccination, and then a reduction in the healthcare provided for $\mathrm{HI}$ children, and consequently more exposure with NVT serotypes. Therefore, it is necessary to healthcare provider and care-givers of $\mathrm{HI}$ children be aware about this type of false assurance.

Although we tried to study children under 7 years of age, which was referred to as a homogeneous age group in previous studies [41, 42], our results showed that the age group can affect the efficacy and effectiveness of vaccines in both $\mathrm{HI}$ and HUI children. Although the study results showed that older HI children had the lowest efficacy compared to children under 2 years old, this result may be due to the length of follow-up time (around 6 years VS less than 2 years) and is not an follow-up adjusted valuable result [26]. However, it may be an indicating evidence on the need of booster doses to increase the vaccine effectiveness among older children.

The results of this study also showed that vaccination schedule could have an effect on vaccine's effectiveness. 
Study

ID

Rate Ratio (95\% Cl)

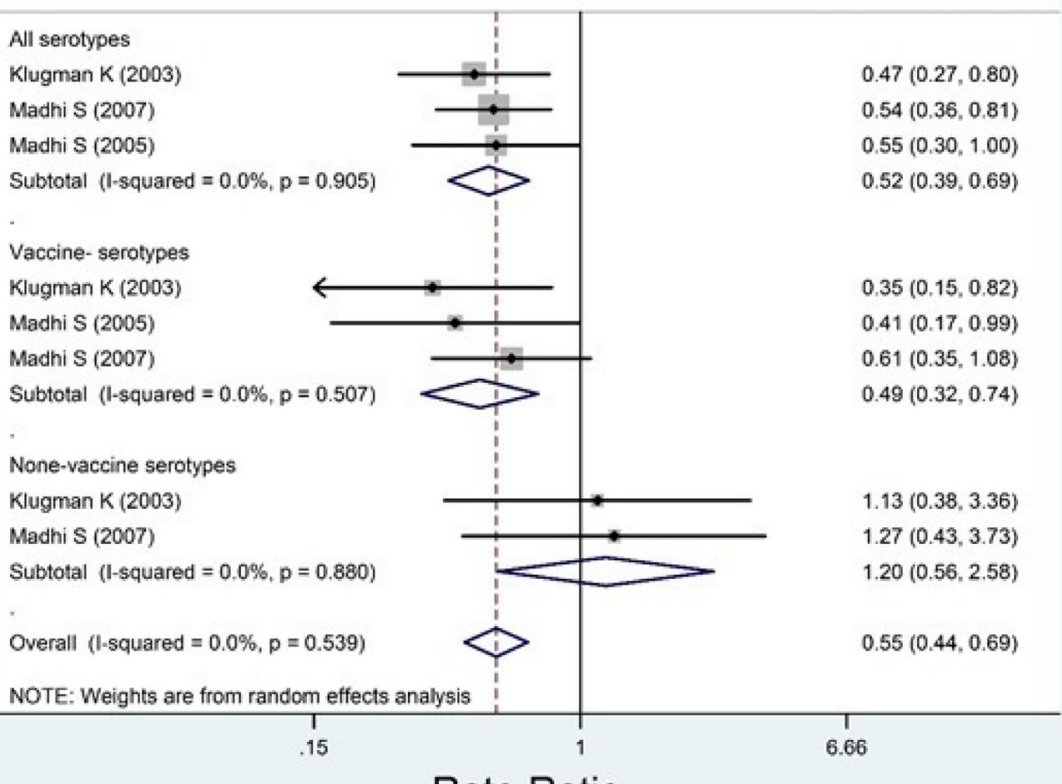

Rate Ratio

Fig. 4 Forest plot of the efficacy (\% VE) of pneumococcal conjugate vaccine against invasive pneumococcal disease among HIV-infected children according to randomized trials

Study

ID

\section{All serotypes}

Klugman K (2003)

Madhi S (2005)

Madhi S (2007)

Subtotal (1-squared $=0.0 \%, p=0.979$ )

Vaccine-serotypes

Klugman K (2003)

Madhi S (2007)

Madhi S (2005)

Subtotal (l-squared $=0.0 \%, p=0.836$ )

None-vaccine serotypes

Klugman K (2003)

Madhi S (2007)

Subtotal (1-squared $=. \%, p=$,)

Overall (I-squared $=13.2 \%, p=0.329$ )

NOTE: Weights are from random effects analysis

$$
.0113
$$

Rate Ratio (95\% Cl)

$0.58(0.26,1.31)$

$0.62(0.20,1.92)$

$0.65(0.32,1.30)$

$0.62(0.38,1.00)$

$0.17(0.04,0.77)$

$0.22(0.08,0.66)$

$0.33(0.07,1.60)$

$0.23(0.11,0.49)$

$4.00(0.18,88.76)$

(Excluded)

$4.00(0.18,88.76)$

$0.47(0.30,0.74)$

\section{Rate Ratio}

Fig. 5 Forest plot of the efficacy (\% VE) of pneumococcal conjugate vaccine against invasive pneumococcal disease among HIV-uninfected children according to randomized trials 
Table 2 Effectiveness or efficacy (95\% CI) of PCVs against invasive pneumococcal disease (IPD) according to different study designs, among HIV-infected and HIV-uninfected children

\begin{tabular}{|c|c|c|c|c|}
\hline \multirow{2}{*}{$\begin{array}{l}\text { Pneumococcal } \\
\text { serotypes }\end{array}$} & \multirow{2}{*}{$\begin{array}{l}\text { HIV } \\
\text { status }\end{array}$} & \multicolumn{3}{|l|}{$\underline{\text { Study design }}$} \\
\hline & & Randomized trial & Case-control & Pre-post \\
\hline \multirow[t]{2}{*}{ All types } & $\mathrm{HI}$ & $47.9(30.7,60.9)$ & $22.6(-80.0,66.8)$ & NA \\
\hline & $\mathrm{HUI}$ & $38.0(-0.1,61.7)$ & $43.0(12.2,63.0)$ & NA \\
\hline \multirow[t]{2}{*}{ Vaccine types } & $\mathrm{HI}$ & $51.0(25.9,67.7)$ & $7.7(-66.7,48.9)$ & NA \\
\hline & $\mathrm{HUI}$ & $77.3(50.9,89.5)$ & $80.0(70.4,86.5)$ & NA \\
\hline \multirow[t]{2}{*}{ Non-vaccine types } & $\mathrm{HI}$ & $-20.0(-158,44.2)$ & $-402.8(-1856,-29.2)^{a}$ & $21.3(-9.5,43.5)$ \\
\hline & HUI & $-300(-8776,82.0)$ & $-21.1(-147.8,40.9)$ & $-12.5(-46.5,13.6)^{b}$ \\
\hline
\end{tabular}

NA Meta-analysis was not applicable due to high heterogeneity, HI HIV-infected, HUI HIV-uninfected

${ }^{\mathrm{a}}$ For children younger than 2.5 years

${ }^{\mathrm{b}}$ For PCV7 and PCV13, but not for other vaccines

This finding is in agreement with the results of previous studies about the necessity of booster dose in the vaccination program for pneumococcal diseases [43-45]. Besides, the valency of vaccine used in the vaccination program caused heterogeneity in effectiveness, especially among HI children, as these values for PCV7 and PCV13 were $7.8 \%$ and $-251 \%$, respectively. At the same time, PCV13 contains serotypes which were replaced a few years after the PCV7 vaccination in routine vaccination programs [46, 47]. Higher effectiveness of PCV7 may be due to higher herd immunity that is expected as time pass from the introduction of the PCV7 vaccination program [16, 33]. The lower value of effectiveness for PCV13 compared with PCV7, which only belongs to HI children, could be a further reason on the faster and higher replacement of non-vaccine pneumococcal serotypes among HI children. Accordingly, it seems that increase in the valency of the PCVs may not be a single effective measure to prevent the IPDs and it should be belong with other interventions.

Another leading determinant of heterogeneity in observational studies was a methodological factor - the IPD diagnosis method. As Madhi et al. [27] has shown the specificity and sensitivity of various methods for the diagnosis of pneumonia are so different $[48,49]$. Therefore, it is necessary to separate the methods appropriate for therapeutic purposes from those suitable for public health goals.
Several randomized trials have been conducted to determine the impact of the PCV7 and PCV13 in HI and HUI children, but these studies have mainly been focused on the quality and quantity of host immune system responses to the vaccines, and not to the incidence rate of IPD among vaccinated children [15, 50-52]. Therefore, the available effect measures are limited to the PCV9.

We were unable to subgroup analysis for strata by dose of vaccine and vaccination schedule on the effectiveness of vaccination due to inadequacy of the number of individual studies. In addition, although we searched for data on the effectiveness of PCV against types of IPD (i.e. meningitis, sepsis, and bacteremia) no individual data was available in this regard.

We could not find any evidence of influential study and/or publication bias based on the sensitivity analysis and Egger's test for publication bias. Accordingly, the results of the study are generalizable. As all studies except for one were conducted in the South Africa, the results of the study might be challengeable to be used in other countries; as a matter of course, it was because of the limitation of existing evidence.

\section{Conclusion}

Effectiveness of PCV against IPD was at -6.2 and $65.1 \%$ in HIV-infected, and -uninfected children, respectively. Its effectiveness against VT IPD among HI children was much less than its efficacy. Its effectiveness among HUI

Table 3 Effectiveness ( $95 \% \mathrm{Cl}$ ) of pneumococcal conjugate vaccine according to the case-control studies by HIV infection status and vaccine valency

\begin{tabular}{|c|c|c|c|c|}
\hline HIV status & $\mathrm{PCV}^{\mathrm{a}}$ & PCV7 & PCV13 & Overall \\
\hline $\mathrm{HI}$ & $10.4(-100.1,60.0)$ & $7.8(-68.2,49.5)$ & $-251(-1944,40.0)$ & $-6.2 \%(-67.6,32.7)$ \\
\hline $\mathrm{HUI}$ & $80.7(47.3,90.1)$ & $60.5(30.0,77.7)^{b}$ & $57.8(0.5,82.1)$ & $65.1 \%(47.3,76.9)$ \\
\hline
\end{tabular}

HI HIV-infected, HUI HIV-uninfected, PCV pneumococcal conjugate vaccine

a Unspecified vaccine valency in primary studies

${ }^{\mathrm{b}}$ Meta-analysis was done despite of moderate heterogeneity (I-squared around 50\%); more details in Additional file 1 
children was greater than its efficacy and it probably indicates the herd immunity of the PCV for HUI children but not for HI children. Not only does the vaccine not prevent IPD among HI children, it can lead to a rapid and high increase of vaccine-serotype and non-vaccine serotype cases in these children, either. The effectiveness of PCV13 among HI children was estimated as $-250 \%$ against all pneumococcal serotypes IPD.

\section{Additional file}

Additional file 1: Results of subgroup analysis, in addition of

publication bias and influential observation diagnostics. (DOCX 508 kb)

\section{Abbreviations}

ART: Antiretroviral Therapy; AT IPD: All Serotypes; HI: Children with HIV infection; HUI: Children Without HIV Infection; IPD): Invasive Pneumococcal Disease; OR: Odds Ratio; PCV: Pneumococcal Conjugate Vaccination; PPVs: Pneumococcal Polysaccharide Vaccines; PRISMA: Reporting Items for Systematic Reviews and Meta-Analyses; RR: Relative Risk; VE \%: Effectiveness; VT IPD: Vaccine Serotype IPD; VT IPD: Vaccine Serotypes

\section{Acknowledgments}

We would thank to Dr. Mohammad Karamouzian from the University of British Colombia for his valuable comments.

\section{Authors' contributions}

$\mathrm{AH}$ and HMV designed the study. HMV and HB searched for primary publications, screened and appraised primary studies. HMV and HB extracted the data. HMV analyzed the data and wrote the study manuscript. All authors read the manuscript and participated in the preparation of the final version of the manuscript. All authors read and approved the final manuscript.

\section{Funding}

No fund was available for this study.

\section{Availability of data and materials}

The datasets used and analyzed during the current study are available from the corresponding author on reasonable request.

\section{Ethics approval and consent to participate}

As this study is a systematic review and meta- analysis, it is not applicable.

\section{Consent for publication}

Not applicable

\section{Competing interests}

The authors declare that they have no competing interests.

\section{Author details}

${ }^{1}$ Molecular Biology Research Center, Systems Biology and Poisonings Institute, Baqiyatallah University of Medical Sciences, Tehran, Iran. ${ }^{2}$ Chemical Injuries Research Center, Systems Biology and Poisonings Institute, Baqiyatallah University of Medical Sciences, Tehran, Iran.

Received: 10 May 2019 Accepted: 26 July 2019

Published online: 05 August 2019

\section{References}

1. Jones N, Huebner R, Khoosal M, Crewe-Brown H, Klugman K. The impact of HIV on Streptococcus pneumoniae bacteraemia in a south African population. AIDS. 1998;12:2177-84.

2. Theodoratou E, McAllister DA, Reed C, Adeloye DO, Rudan I, Muhe LM, et al. Global, regional, and national estimates of pneumonia burden in HIVinfected children in 2010: a meta-analysis and modelling study. Lancet Infect Dis. 2014;14:1250-8.
3. Madhi SA, Petersen K, Madhi A, Wasas A, Klugman KP. Impact of human immunodeficiency virus type 1 on the disease spectrum of Streptococcus pneumoniae in south African children. Pediatr Infect Dis J. 2000;19:1141-7.

4. Von Mollendorf C, Von Gottberg A, Tempia S, Meiring S, De Gouveia L, Quan $V$, et al. Increased risk for and mortality from invasive pneumococcal disease in HIV-exposed but uninfected infants aged $<1$ year in South Africa, 2009-2013. Clin Infect Dis. 2015;60:1346-56.

5. von Gottberg A, de Gouveia L, Tempia S, Quan V, Meiring S, von Mollendorf $C$, et al. Effects of vaccination on invasive pneumococcal disease in South Africa. N Engl J Med. 2014;371:1889-99.

6. Nunes MC, von Gottberg A, de Gouveia L, Cohen C, Kuwanda L, Karstaedt AS, et al. Persistent high burden of invasive pneumococcal disease in south African HIV-infected adults in the era of an antiretroviral treatment program. PLoS One. 2011;6:e27929.

7. Andrews NJ, Waight PA, George RC, Slack MP, Miller E. Impact and effectiveness of 23-valent pneumococcal polysaccharide vaccine against invasive pneumococcal disease in the elderly in England and Wales. Vaccine. 2012;30:6802-8.

8. Poehling KA, Talbot TR, Griffin MR, Craig AS, Whitney CG, Zell E, et al. Invasive pneumococcal disease among infants before and after introduction of pneumococcal conjugate vaccine. Jama. 2006;295: 1668-74.

9. Whitney CG, Farley MM, Hadler J, Harrison LH, Bennett NM, Lynfield R, et al. Decline in invasive pneumococcal disease after the introduction of proteinpolysaccharide conjugate vaccine. N Engl J Med. 2003;348:1737-46.

10. Pilishvili T, Lexau C, Farley MM, Hadler J, Harrison LH, Bennett NM, et al. Sustained reductions in invasive pneumococcal disease in the era of conjugate vaccine. J Infect Dis. 2010;201:32-41.

11. Latifi-Navid H, Latifi-Navid S, Mostafaiy B, Jamalkandi SA, Ahmadi A. Pneumococcal disease and the effectiveness of the PPV23 vaccine in adults: a two-stage Bayesian meta-analysis of observational and RCT reports. Sci Rep. 2018:8:11051.

12. O'Brien KL, Hochman M, Goldblatt D. Combined schedules of pneumococcal conjugate and polysaccharide vaccines: is hyporesponsiveness an issue? Lancet Infect Dis. 2007;7:597-606.

13. Borrow R, Heath PT, Siegrist C-A. Use of pneumococcal polysaccharide vaccine in children: what is the evidence? Curr Opin Infect Dis. 2012;25:292-303.

14. Warnatz K. Dissecting CXCR5+ T cell populations-on the quest for a better understanding of B cell help during T dependent antibody responses. Eur J Immunol. 2006;36:1662-4.

15. Madhi SA, Klugman KP, Kuwanda L, Cutland C, Käyhty H, Adrian P. Quantitative and qualitative anamnestic immune responses to pneumococcal conjugate vaccine in HIV-infected and HIV-uninfected children 5 years after vaccination. J Infect Dis. 2009;199:1168-76.

16. Feikin DR, Kagucia EW, Loo JD, Link-Gelles R, Puhan MA, Cherian T, et al. Serotype-specific changes in invasive pneumococcal disease after pneumococcal conjugate vaccine introduction: a pooled analysis of multiple surveillance sites. PLoS Med. 2013;10:e1001517.

17. Weinberger DM, Malley R, Lipsitch M. Serotype replacement in disease after pneumococcal vaccination. Lancet. 2011;378:1962-73.

18. Cohen C, von Mollendorf C, de Gouveia L, Lengana S, Meiring S, Quan V, et al. Effectiveness of the 13-valent pneumococcal conjugate vaccine against invasive pneumococcal disease in south African children: a case-control study. Lancet Glob Health. 2017;5:e359-e69.

19. Cohen C, von Mollendorf C, de Gouveia L, Naidoo N, Meiring S, Quan $V$, et al. Effectiveness of 7-valent pneumococcal conjugate vaccine against invasive pneumococcal disease in HIV-infected and -uninfected children in South Africa: a matched case-control study. Clin Infect Dis. 2014:59:808-18.

20. Klugman KP, Madhi SA, Huebner RE, Kohberger R, Mbelle N, Pierce N. A trial of a 9-valent pneumococcal conjugate vaccine in children with and those without HIV infection. N Engl J Med. 2003;349:1341-8.

21. Jallow S, Madhi SA. Pneumococcal conjugate vaccine in HIV-infected and HIV-exposed, uninfected children. Expert Review Vaccines. 2017;16:453-65.

22. Bliss SJ, O'Brien KL, Janoff EN, Cotton MF, Musoke P, Coovadia $H$, et al. The evidence for using conjugate vaccines to protect HIV-infected children against pneumococcal disease. Lancet Infect Dis. 2008;8:67-80.

23. Liberati A, Altman DG, Tetzlaff J, Mulrow C, Gotzsche PC, loannidis JP, et al. The PRISMA statement for reporting systematic reviews and metaanalyses of studies that evaluate health care interventions: explanation and elaboration. PLoS Med. 2009;6:e1000100. 
24. Higgins JP, Altman DG, Gøtzsche PC, Jüni $P$, Moher $D$, Oxman AD, et al. The Cochrane Collaboration's tool for assessing risk of bias in randomised trials. Bmj. 2011;343:d5928.

25. Stang A. Critical evaluation of the Newcastle-Ottawa scale for the assessment of the quality of nonrandomized studies in meta-analyses. Eur J Epidemiol. 2010:25:603-5.

26. Madhi SA, Adrian P, Kuwanda L, Jassat W, Jones S, Little T, et al. Long-term immunogenicity and efficacy of a 9-valent conjugate pneumococcal vaccine in human immunodeficient virus infected and non-infected children in the absence of a booster dose of vaccine. Vaccine. 2007;25:2451-7.

27. Madhi SA, Kuwanda L, Cutland C, Klugman KP. The impact of a 9-valent pneumococcal conjugate vaccine on the public health burden of pneumonia in HIV-infected and -uninfected children. Clin Infect Dis. 2005;40:1511-8.

28. von Mollendorf C, Cohen C, de Gouveia L, Naidoo N, Meiring S, Quan V, et al. Risk factors for invasive pneumococcal disease among children less than 5 years of age in a high HIV prevalence setting, South Africa, 2010 to 2012. Pediatr Infect Dis J. 2015;34:27-34.

29. Steenhoff AP, Wood SM, Rutstein RM, Wahl A, McGowan KL, Shah SS. Invasive pneumococcal disease among human immunodeficiency virusinfected children, 1989-2006. Pediatr Infect Dis J. 2008;27:886-91.

30. Nzenze SA, Madhi SA, Shiri T, Klugman KP, de Gouveia L, Moore DP, et al. Imputing the direct and indirect effectiveness of childhood pneumococcal conjugate vaccine against invasive pneumococcal disease by surveying temporal changes in nasopharyngeal pneumococcal colonization. Am J Epidemiol. 2017;186:435-44.

31. Halloran ME, Haber M, Longini IM Jr, Struchiner CJ. Direct and indirect effects in vaccine efficacy and effectiveness. Am J Epidemiol. 1991;133:323-31.

32. Fine P, Eames K, Heymann DL. "Herd immunity": a rough guide. Clin Infect Dis. 2011:52:911-6.

33. Shiri T, Datta S, Madan J, Tsertsvadze A, Royle P, Keeling MJ, et al. Indirect effects of childhood pneumococcal conjugate vaccination on invasive pneumococcal disease: a systematic review and meta-analysis. Lancet Glob Health. 2017;5:e51-e9.

34. Sigurdsson S, Erlendsdóttir H, Quirk SJ, Kristjánsson J, Hauksson K, Andrésdóttir BDI, et al. Pneumococcal vaccination: direct and herd effect on carriage of vaccine types and antibiotic resistance in Icelandic children. Vaccine. 2017;35:5242-8.

35. Smith C, Ding L, Gorbach P, Franco E, Kahn J. Who's not protected in the herd? Factors associated with vaccine-type HPV in unvaccinated women. J Pediatr Adolesc Gynecol. 2017;31:89-93.

36. Balsells E, Guillot L, Nair H, Kyaw MH. Serotype distribution of Streptococcus pneumoniae causing invasive disease in children in the post-PCV era: a systematic review and meta-analysis. PLoS One. 2017;12:e0177113.

37. Muñoz-Almagro C, Jordan I, Gene A, Latorre C, Garcia-Garcia JJ, Pallares R. Emergence of invasive pneumococcal disease caused by nonvaccine serotypes in the era of 7-valent conjugate vaccine. Clin Infect Dis. 2008;46:174-82.

38. Weatherholtz R, Millar EV, Moulton LH, Reid R, Rudolph K, Santosham M, et al. Invasive pneumococcal disease a decade after pneumococcal conjugate vaccine use in an American Indian population at high risk for disease. Clin Infect Dis. 2010;50:1238-46.

39. Pilishvili T, Zell ER, Farley MM, Schaffner W, Lynfield R, Nyquist A-C, et al. Risk factors for invasive pneumococcal disease in children in the era of conjugate vaccine use. Pediatrics. 2010;126:e9-17.

40. Singleton RJ, Hennessy TW, Bulkow LR, Hammitt LL, Zulz T, Hurlburt DA, et al. Invasive pneumococcal disease caused by nonvaccine serotypes among Alaska native children with high levels of 7-valent pneumococcal conjugate vaccine coverage. Jama. 2007;297:1784-92.

41. Bamford A, Kelleher P, Lyall H, Haston M, Zancolli M, Goldblatt D, et al. Serological response to 13 -valent pneumococcal conjugate vaccine in children and adolescents with perinatally acquired HIV infection. AIDS (London, England). 2014;28:2033.

42. King JC Jr, Borkowsky W, Mahidhara N, Madore D, Shapiro ED, Rutstein RM, et al. Group-specific antibody levels surrounding invasive pneumococcal illness in children infected with human immunodeficiency virus. J Infect Dis. 2000;181:1817-21.

43. Goldblatt D, Southern J, Ashton L, Richmond P, Burbidge P, Tasevska J, et al. Immunogenicity and boosting after a reduced number of doses of a pneumococcal conjugate vaccine in infants and toddlers. Pediatr Infect Dis J. 2006:25:312-9.

44. van Gils EJ, Veenhoven RH, Hak E, Rodenburg GD, Bogaert D, ljzerman EP, et al. Effect of reduced-dose schedules with 7-valent pneumococcal conjugate vaccine on nasopharyngeal pneumococcal carriage in children: a randomized controlled trial. Jama. 2009;302:159-67.

45. Vestrheim DF, Løvoll $\varnothing$, Aaberge IS, Caugant DA, Høiby EA, Bakke H, et al. Effectiveness of a $2+1$ dose schedule pneumococcal conjugate vaccination programme on invasive pneumococcal disease among children in Norway. Vaccine. 2008:26:3277-81.

46. Miller E, Andrews NJ, Waight PA, Slack MP, George RC. Herd immunity and serotype replacement 4 years after seven-valent pneumococcal conjugate vaccination in England and Wales: an observational cohort study. Lancet Infect Dis. 2011;11:760-8.

47. Miller E, Andrews NJ, Waight PA, Slack MP, George RC. Effectiveness of the new serotypes in the 13-valent pneumococcal conjugate vaccine. Vaccine. 2011;29:9127-31.

48. Avni T, Mansur N, Leibovici L, Paul M. PCR using blood for diagnosis of invasive pneumococcal disease: systematic review and meta-analysis. J Clin Microbiol. 2010;48:489-96.

49. Musher DM, Montoya R, Wanahita A. Diagnostic value of microscopic examination of gram-stained sputum and sputum cultures in patients with bacteremic pneumococcal pneumonia. Clin Infect Dis. 2004;39:165-9.

50. Nunes MC, Madhi SA. Safety, immunogenicity and efficacy of pneumococcal conjugate vaccine in HIV-infected individuals. Hum Vaccin Immunother. 2012:8:161-73.

51. Madhi SA, Kuwanda L, Cutland C, Holm A, Käyhty H, Klugman KP. Quantitative and qualitative antibody response to pneumococcal conjugate vaccine among African human immunodeficiency virus-infected and uninfected children. Pediatr Infect Dis J. 2005;24:410-6.

52. Spoulou VI, Tsoumas DL, Papaevangelou VG, Mostrou Gl, Theodoridou MC. Immunogenicity and immunological memory induced by a 7-valent pneumococcal CRM197 conjugate vaccine in symptomatic HIV-1 infected children. Vaccine. 2005;23:5289-93.

\section{Publisher's Note}

Springer Nature remains neutral with regard to jurisdictional claims in published maps and institutional affiliations.

Ready to submit your research? Choose BMC and benefit from:

- fast, convenient online submission

- thorough peer review by experienced researchers in your field

- rapid publication on acceptance

- support for research data, including large and complex data types

- gold Open Access which fosters wider collaboration and increased citations

- maximum visibility for your research: over $100 \mathrm{M}$ website views per year

At BMC, research is always in progress.

Learn more biomedcentral.com/submissions 